\title{
Patopsicologia Experimental: Abordagem histórico-cultural para o entendimento do sofrimento mental
}

Maria Aparecida Santiago da Silva. Centro de Atenção Psicossocial de Marialva. Silvana Calvo Tuleski. Universidade Estadual de Maringá.

\section{Resumo}

Neste artigo, de natureza conceitual e metodológica, busca-se apresentar os princípios iniciais acerca do estudo do adoecimento psíquico a partir da Psicologia Histórico-Cultural. Especificamente, será apresentada a Patopsicologia Experimental, elaborada pela psicóloga lituana Bluma V. Zeigarnik, campo de conhecimento ainda bastante desconhecido no Brasil. Esta disciplina psicológica, cuja base metodológica assenta-se no materialismo histórico e dialético, é intermediária entre a psicologia e a psiquiatria, tendo sido desenvolvida, particularmente, na União Soviética. A Patopsicologia Experimental aborda os transtornos mentais como alterações da atividade mental, considerando seu caráter histórico e dependente das relações sociais. A personalidade é tomada como objeto de investigação principal, tendo em vista sua intrínseca relação com a atividade do homem e as condições sociais nas quais ele se desenvolve e, também, adoece. O estudo pretende sistematizar possibilidades de atuação no campo da saúde mental, a partir dessa perspectiva teórica, superando princípios biológicos e medicalizantes.

Palavras-chave: psicologia histórico-cultural; saúde mental; sofrimento mental.

\begin{abstract}
Experimental abnormal Psychology: Historical-cultural approach to understanding mental suffering. This article, from conceptual and methodological nature, aims presenting the initial principles about the study of mental illness from the Historical-Cultural Psychology. In particular, it will present the Experimental Abnormal Psychology, elaborated by the Lithuanian psychologist Bluma V. Zeigarnik, which is a field of knowledge mostly unknown in Brazil. This psychological discipline, whose methodological base relies on the historical and dialectical materialism, is situated between psychology and psychiatry, and has been developed particularly in the Soviet Union. The Experimental Abnormal Psychology discusses about mental disorders, like changes in mental activity, considering its historical character and depends on the social relations. The personality is taken as an object of primary research, in view of its intrinsic relationship with the activity of the man and the social conditions in which they develop and also gets sick. The study aims to systematize the possibilities of action in the mental health field, from that theoretical perspective, overcoming the biological and medicals principles.
\end{abstract}

Keywords: cultural-historical psychology; mental health; mental suffering.

\section{Resumen}

Patopsicología Experimental: Enfoque histórico-cultural para entender el sufrimiento mental. Este artículo, de naturaleza conceptual y metodológica, busca presentar los fundamentos iniciales acerca del estudio dela psiquis enfermiza, a partir de la Psicología Histórico Cultural. Específicamente, se presentará la Patopsicología Experimental, elaborada por la psicóloga lituana Bluma V. Zeigarnik, un campo de conocimiento aún bastante desconocido en Brasil. Esta disciplina de la psicología, cuya base metodológica se asienta en el materialismo histórico y dialéctico, es intermediaria entre la psicología y la psiquiatría, habiendo sido desarrollada, particularmente, en la Unión Soviética. La Patopsicología Experimental aborda los trastornos mentales como alteraciones de la actividad mental, considerando su carácter histórico y dependiente de las relaciones sociales. La personalidad se toma como objeto principal de investigación, en vista de su relación intrínseca con la actividad del hombre y las condiciones sociales en las cuales se desarrolla y, también, se enferma. El estudio pretende sistematizar posibilidades de actuación en el campo de la salud mental, a partir de la perspectiva teórica presentada, superando principios biológicos y de medicalización.

Palabras clave: psicología histórico-cultural; salud mental; sufrimiento mental. 
No campo da saúde mental, tem sido cada vez mais notável as queixas relacionadas ao sofrimento mental, em diversos níveis de gravidade, sendo os casos de transtornos mentais, tratados, tantas vezes ainda, sob o viés biológico e farmacológico. Conforme dados da Organização Mundial da Saúde [OMS] (2001), os transtornos mentais são responsáveis por cinco das dez maiores causas de incapacitação no mundo do trabalho, referindo-se à depressão, ao transtorno bipolar, à esquizofrenia, ao alcoolismo e ao transtorno obsessivo-compulsivo.

Numa concepção naturalizada de sociedade, transformando o que é histórico e social em algo natural, a psicologia, muitas vezes, tem atuado à serviço das ideologias dominantes vigentes, afirmando as divergências de comportamento como desadaptações, no crescente processo de patologização da vida e culpabilização dos indivíduos em particular. Sob o paradigma biomédico, tão apropriado pela psiquiatria, o entendimento e cuidado do sofrimento mental das pessoas vêm sendo feitos por meio de sistemas de classificação dos transtornos que ficam restritos às descrições de sinais e sintomas de manuais para diagnósticos ${ }^{1}$. Ao invés de serem utilizados como mais um instrumento para elaboração e planejamento do plano terapêutico do sujeito, dentre muitos outros, têm sido aplicados de forma taxativa, descritiva e encerrados em si mesmos.

Boarini (2006) afirma que este paradigma biomédico faz com que o transtorno mental seja um distúrbio compreendido como algo em si, acometendo determinado indivíduo, fortalecendo o papel do médico e da medicação como meio prioritário de tratamento, assim como fortalece a etiologia orgânica e a-histórica. Em grande parte, estas explicações hegemônicas baseiam-se no que é fenomênico, pelo estudo do que se manifesta e na classificação a partir dos traços exteriores, sem a análise do ponto de vista genético, que prioriza a investigação a partir do desenvolvimento dos processos psicológicos sob condições socioculturais.

Diante disso, deparamo-nos com a necessidade de enfrentamento dessa situação que se intensifica ainda mais frente à realidade dos homens que, nas relações de produção e de alienação atuais, encontram-se desapropriados de sua força de trabalho e de si mesmos, pelo modo que a vida se organiza na sociedade. $O$ presente artigo busca articular essa realidade com os processos de sofrimento mental dos sujeitos, a partir da contribuição inicial da Psicologia Histórico-Cultural para o campo da saúde mental, dada na disciplina Patopsicologia Experimental. Em termos introdutórios, é preciso antes, caracterizar, mesmo que de forma sucinta, essa realidade compreendida como plano social complexo na qual os homens encontram-se e adoecem, assim como também explicitar qual o posicionamento teórico que embasa este estudo.

Sobre o primeiro aspecto, Vygotsky ressalta a mutilação da natureza humana que ocorre na forma de organização da sociedade capitalista, pelo modo como é tomado o trabalho, entendido como atividade vital humana. $\mathrm{O}$ autor aponta a inversão que ocorre no sistema produtivo, tornando o trabalhador alienado em suas capacidades humanas ao invés de ser o propulsor de tais aptidões, uma relação que, desta forma organizada, causa prejuízos à formação da personalidade. A personalidade, conforme o autor, "é formada basicamente pela influência das relações sociais" (Vygotsky, 1930, s/p) e prejudicada, portanto, nessa organização descrita.

A esse respeito, o sociólogo Antunes (2011), ao tomar o trabalho como ponto inicial do processo de humanização do ser social, afirma que na sociedade capitalista, essa atividade é degradada e desvalorizada. Nas palavras do autor, o trabalho torna-se "estranhado. O que deveria se constituir na finalidade básica do ser social - a sua realização no e pelo trabalho - é pervertido e depauperado. O processo de trabalho se converte em meio de subsistência" (Antunes, 2011, p. 144, grifos do autor).

Nesse sentido, de acordo com o referido autor, a forma de organização do trabalho na sociedade capitalista caracteriza-se pela lógica da flexibilidade, pelo trabalho desregulamentado e informal (desprovido de direitos e de carteira de trabalho), intensificação de formas de extração de trabalho, formas coercitivas de controle e avaliação, imprevisibilidade, ampliação das terceirizações, noções de tempo e espaço sofrendo metamorfoses, dentre outras. Há, portanto, a desrealização do ser social, a degradação e o não reconhecimento do homem em sua própria produção, numa lógica de exclusão e consumo, o que, portanto, compromete a saúde mental das pessoas.

Essas considerações embasam, portanto, a afirmação de que nesse modo de viver, que vem apresentando índices cada vez maiores de adoecimento mental entre as pessoas, como apresentado pela OMS (2001), os processos de formação da personalidade considerados saudáveis vêm sendo cada vez menos frequentes. Diante disso, a partir da Psicologia Histórico- 
Cultural, sob os princípios do materialismo histórico e dialético ${ }^{2}$, o adoecimento psíquico é tomado como constituído histórica e socialmente, o que é ratificado pelas considerações apresentadas acima. Se o ser humano se humaniza no interior das relações sociais por meio de sua atividade vital e metabólica com a natureza - o trabalho -, quando esta forma de atividade encontra-se alienada e precarizada, as possibilidades para o desenvolvimento pleno da personalidade humana encontram-se obstaculizadas.

Partindo dos pressupostos acima sintetizados, o presente artigo apresenta uma sistematização que permite a compreensão do sofrimento e adoecimento mental a partir das contribuições da Psicologia HistóricoCultural. Dividido em duas partes, o artigo tratará, inicialmente, da retomada do contexto histórico soviético vinculado ao entendimento de questões acerca da saúde mental. Posteriormente, como assunto principal, será abordada a disciplina psicológica Patopsicologia Experimental, de Bluma V. Zeigarnik (1900-1988). Os estudos desta psicóloga lituana, discípula de Vigotski, ainda são pouco explorados e divulgados no Brasil, o que deve ser revertido, dada a sua importância na defesa de uma compreensão histórica dos princípios genético-causais do sofrimento e adoecimento mental ${ }^{3}$.

É válido ressaltar que, por se tratar de uma retomada histórica acerca da Patopsicologia Experimental, desenvolvida a partir de 1960, o artigo pauta-se quase que com exclusividade no referencial teórico de Vigotski e Zeigarnik. Este fato justifica a utilização de fontes bibliográficas das décadas de 1930 a 1980 do século passado, muitas delas sem edições mais atuais que possam ser referenciadas. $O$ mesmo ocorre com relação às fontes históricas que possibilitaram a reconstrução dos acontecimentos políticos e econômicos com seus desdobramentos para o campo da psiquiatria e psicologia soviética.

\section{Contexto histórico - A sociedade russa e soviética no enfretamento dos transtornos mentais e suas demandas históricas}

As relações entre a psicologia e a psiquiatria russas e soviéticas, desde o final do governo czarista, no século XIX, até o período de desestalinização, abrangem grandes e importantes transformações na realidade social do país, que foram refletidas diretamente no campo científico. Nesse sentido, a psiquiatria e a psicologia, como toda ciência em um período dado, refletiram as contradições do ambiente social da época, no acompanhamento das mudanças históricas. Aqui, serão expostos brevemente os aspectos concernentes ao período pós-revolucionário, que são mais relevantes para o entendimento e visualização do processo de formação da Patopsicologia Experimental.

Desse modo, logo após a Revolução de 1917, período governado por Lênin, houve o incentivo e investimento na produção de conhecimento nos vários ramos da arte e da ciência, precedida pela revolução econômica e social, implicando, portanto, na cultural. Sob o projeto coletivo de formação de uma sociedade comunista, ressalta-se o papel fundamental da pedagogia e da psicologia nesse projeto de novo homem, diante do cenário de guerra civil e necessidade de reconstrução econômica e social. Os problemas relacionados à psiquiatria tiveram atenção após o atendimento dessa demanda mais urgente e inicial.

$\mathrm{Na}$ década de 1920, começaram as exposições e organização dos psicólogos materialistas soviéticos na formação de uma psicologia marxista-leninista, ao passo que se desenvolviam os estudos relacionados à psicopatologia, chamados na União Soviética de Patopsicologia, desde o final do século XIX. Na Rússia, a psicopatologia desenvolveu-se como novo ramo da psicologia, pautado nas ciências naturais e pelo desenvolvimento da psiquiatria, começando com o fisiólogo V. M. Bekhterev (1857-1927) e o método experimental. Anos mais tarde, Zeigarnik desenvolveria a Patopsicologia Experimental, sob os princípios do materialismo histórico e dialético.

Conforme Wortis (1953) e Rojlin (s.d.), no projeto da sociedade comunista, a psiquiatria esteve voltada aos aspectos relativos à saúde psíquica da população da URSS após o período mais crítico da guerra civil. Por sua vez, à psicologia foi atribuído o papel de formação do novo homem, que deveria ser compatível ao desenvolvimento de uma sociedade comunista, o que fez com que ficasse mais próxima à educação, voltada para o desenvolvimento da consciência e conduta humana. Desse modo, a psicologia envolvia-se mais com os processos educativos, enquanto que os aspectos relativos à saúde mental ficaram mais relegados aos cuidados da fisiologia e da psiquiatria soviética.

Por sua vez, sob o poder de Stálin, o processo de transformação social foi marcado por uma forte censura e dirigismo político, que levaram à intervenção estatal ainda maior no campo científico e a centralização nas práticas em saúde mental. Esse período ditatorial 
caracterizou-se por expurgos, assassinatos e perseguições exercidos pelo Partido (Lavretsky, 1998). O setor da psiquiatria estruturou-se como mais um órgão a serviço da polícia na execução de medidas organizativas contra os opositores, na prisão de dissidentes políticos em hospitais psiquiátricos e nos campos de trabalho forçado. Conforme Wortis (1953), as instituições psiquiátricas tinham a função política e econômica, dependendo do que se pretendia evitar ou sucumbir nas relações entre os homens, no exercício de um poder de punição aos indivíduos não adoecidos mentalmente, mas que perturbavam a ordem política.

Nesse período do governo stalinista, a ciência psicológica soviética, em sua totalidade, sofreu grandes deformações e atrasos em seu desenvolvimento científico. Especificamente, o ano de 1936 foi marcado pela máxima direção e censura partidária no campo científico, na liquidação da pedologia, da psicotécnica, da psicologia do trabalho, acusadas de reacionárias e pseudocientíficas. Conforme Shuare (1990), esse movimento gerou um sério atraso na ciência psicológica soviética, com a proibição das obras de Vigotski e o crescimento das ideias do fisiólogo I. Pavlov (1849 -1936) na ciência, especificamente, na psicologia e na psiquiatria.

Dessa maneira, o campo científico foi tomado pela doutrina pavloviana, no triunfo oficial da interpretação mecanicista e biologizante, principalmente com a proibição da Psicologia Histórico-Cultural. A saúde mental foi relegada ao cuidado da psiquiatria sob o viés fisiológico, com estudos iniciais de Zeigarnik no campo da Patopsicologia Experimental ainda sem muitas perspectivas, pois estavam no caminho contrário à separação imposta entre a psiquiatria e a psicologia. Diante dessas considerações, percebe-se que a psicologia foi descaracterizada de seu objeto de estudo, o homem, inclusive o adoecido psiquicamente, em virtude do valor atribuído à fisiologia e à psiquiatria na sua função de controle exercido no governo stalinista.

Wortis (1953) ressalta a ausência quase completa de temas psicológicos ligados à literatura psiquiátrica russa, em contraste com a produção psiquiátrica soviética. Tal fato demonstra a estreita relação entre a saúde mental, psicopatologia e a psiquiatria, atrelada à fisiologia, de um lado, e a psicologia ligada à formação do homem soviético e à educação, não mais sob o enfoque da Psicologia Histórico-Cultural, mas do pavlovianismo.

Os estudos e intervenções da Patopsicologia Experimental acompanharam todo esse processo histórico na União Soviética, buscando a superação do pensamento fisiológico imposto oficialmente na direção de pensar o desenvolvimento humano normal e patológico a partir da metodologia materialista histórica e dialética. O trabalho de Zeigarnik, por exemplo, mais direcionado ao desenvolvimento da Patopsicologia Experimental ocorreu na década 1960, próximo ao período de institucionalização da psicologia enquanto ciência independente, uma vez que, até então, não pertencia ao quadro da Academia de Ciências da URSS. Até esse período, a ciência psicológica estava subordinada às ciências pedagógicas, ou seja, à Academia de Ciências Pedagógicas da URSS (Almeida, 2008).

Esses avanços possibilitaram o fortalecimento da Psicologia enquanto ciência e as investigações de Zeigarnik obtiveram melhores condições para o seu desenvolvimento, principalmente a partir de sua inserção como docente em Moscou, na década de 1960, posição que Ihe permitiu prosseguir de forma mais sistematizada seus estudos, como será exposto a seguir no presente artigo.

\section{A Patopsicologia Experimental - seus fundamentos e proposições metodológicas}

A Patopsicologia é um campo psicológico desenvolvido na Rússia desde os tempos czaristas até o período da União Soviética. Com Zeigarnik, foi atribuído o princípio metodológico do materialismo histórico e dialético, juntamente com o estudo experimental dos transtornos mentais, o que leva à denominação de Patopsicologia Experimental.

Zeigarnik (citada por Golder, 1986) afirma que em sua carreira profissional atravessou distintas etapas, desde a perspectiva experimental até a teórica, sob a influência de eminentes psicólogos gestaltistas alemães e soviéticos, sendo estes últimos, principalmente, Vigotski, Luria e Leontiev. Golder (1986) traça, de forma sucinta e didática, a trajetória da autora a partir de cinco momentos de sua vida pessoal e profissional.

O primeiro momento refere-se à experiência com o psicólogo alemão Kurt Lewin (1892-1947) na Universidade de Berlim, com seu trabalho de doutorado com o tema da memória, conhecido como "Efeito Zeigarnik". Seguido do período berlinesco, com seu retorno à União Soviética, em 1931, Zeigarnik entrou em contato com a psicologia fundada por Vigotski, com quem compartilhou seus pressupostos filosóficos e metodológicos. 
Conforme Zeigarnik (citada por Golder, 1986), houve por parte de Vigotski uma inclinação para o estudo dos transtornos mentais sem o esquecimento, no entanto, de seu interesse pelo desenvolvimento da psicologia geral, da psicologia dos processos psíquicos superiores, tarefa que constituiu o norte vigotskiano em seus estudos sobre a linguagem e significado. Vigotski, a partir de uma enorme quantidade de material que vinha da patologia, elaborou os trabalhos relativos à esquizofrenia partindo de estudos sobre o processo de formação dos conceitos e de constituição dos sistemas psicológicos, sob o enfoque genético.

No começo da década de 1930, próximo ao final de sua vida, Vigotski aproximou-se de trabalhos da psicologia clínica e psiquiatria, especialmente referentes ao domínio do comportamento desviante em adultos. Baseado em autores como o psiquiatra alemão Ernest Kretschmer (1888-1964) e Kurt Lewin, seus interesses estavam voltados ao estudo da afasia, da esquizofrenia, do mal de Alzheimer, da doença de Parkinson e da doença de Pick (Valsiner \& Van der Veer, 2006). Dessa maneira, a psicologia de Vigotski deu base à explicação de determinados transtornos mentais, que eram tratados apenas no âmbito da psiquiatria, tida como o campo científico competente para lidar com a saúde mental, como exposto anteriormente. Zeigarnik trabalhou com Vigotski nesse período, na segunda etapa de sua história profissional. Esse encontro com a psicologia vigotskiana produziu uma transformação em sua carreira, tornando-se a base de todo o seu trabalho subsequente na Patopsicologia Experimental.

Já na década de 1940, durante os anos da Segunda Guerra Mundial, Zeigarnik vivenciou a terceira etapa de sua trajetória profissional, trabalhando junto aos feridos de guerra na reabilitação de funções psíquicas perdidas ou deterioradas por traumatismo cerebral, em colaboração com Luria. A partir de 1962, a autora dedicou-se ao desenvolvimento da Patopsicologia Experimental, principal ramo atribuído ao seu nome, período que contempla a quarta etapa da trajetória profissional de Bluma V. Zeigarnik. Em sua última etapa de trabalho, na década de 1980, Zeigarnik dedicou-se ao estudo das diferentes teorias da personalidade vigentes no mundo todo (Golder, 1986).

Desse modo, na Patopsicologia Experimental de Zeigarnik há uma grande preocupação pela personalidade do sujeito comprometido pelos transtornos mentais. A autora revisou os conceitos de sintoma e de personalidade, que nos tratados clássicos da psiquiatria eram enfocados como alterações da função psíquica ou, em seu defeito, como alterações dos processos fisiológicos, o que se tornava a inclinação principal da psiquiatria soviética. Por meio dos princípios gerais da psicologia vigotskiana, "a análise do fenômeno psicopatológico contemplará a personalidade total do enfermo e em especial as trocas nos fenômenos tão essenciais como as atitudes, as necessidades e os interesses" (Golder, 1986, p. 78).

A Patopsicologia Experimental foi sendo desenvolvida na União Soviética como um campo do conhecimento com seu próprio objeto, com suas aplicações práticas, seus próprios métodos e grupo de pesquisadores, com base nos pressupostos vigotskianos. A partir dos fundamentos propostos, Zeigarnik (1976/1981) entende que as modificações da atividade psíquica, tanto cognitiva quanto a motivada emocionalmente, não se manifestam como uma consequência imediata da doença mental, mas seguem um complexo caminho de formação e desenvolvimento. Esse posicionamento pode ser vinculado ao método genético, já proposto por Vigotski, na análise da trajetória de vida do sujeito adoecido e os dados adquiridos no experimento psicológico.

Ainda, partindo-se do princípio da Psicologia Histórico-Cultural de que o desenvolvimento cultural não supõe identidade entre a instância biológica e cultural, mas sim um processo no qual o cultural supera por incorporação o biológico, tem-se que o aspecto cultural é o fundamento ontológico do ser social ${ }^{4}$. Nesse sentido, ao tomar o desenvolvimento psíquico como resultado da educação e assimilação da experiência humana acumulada (produção de instrumentos e signos) a partir do intercâmbio social, Zeigarnik (1976/1981) afirma que, em casos patológicos, o biológico assume um papel diferente na pessoa doente do que na saudável, criando condições que conduzem à alteração da atividade mental humana. Para a Patopsicologia Experimental, deve ser mantida a importância das apropriações sociais nesse desenvolvimento, voltando-se à relação dialética entre organismo e meio social no estudo e intervenção das alterações patológicas ao longo do desenvolvimento ontogenético do sujeito adoecido.

Esclarecida essa questão, é necessário tratar, nesse momento, especificamente, das características da Patopsicologia Experimental. Subordinada às regularidades e às leis da psicologia geral, desenvolvidas, particularmente, na URSS, é uma disciplina da ciência psicológica, com valor teórico e prático para a psicologia como para a psiquiatria, sendo, portanto, uma ciência intermediária. Zeigarnik (1969/1979; 1976/1981) 
afirma que a Patopsicologia Experimental parte das leis de desenvolvimento e da estrutura do psiquismo em estado normal. São estas leis gerais que fornecem a determinação das modificações no estado psíquico do sujeito adoecido mentalmente, da alteração em sua capacidade de trabalho e de sua personalidade, para a investigação psicológica. Neste processo, é fundamental verificar as modificações que ocorrem na atividade do sujeito, em sua atitude diante da vida e suas reações ao meio no qual se desenvolve.

Diante dessas considerações, é importante apresentar as diferenças nas duas disciplinas - Patopsicologia Experimental (disciplina psicológica) e Psicopatologia ocidental (ciência médica) - que abordam as alterações psíquicas, a partir de diferentes posições (Golder, 1986; Zeigarnik, 1969/1979, 1976/1981). A Patopsicologia Experimental entende os transtornos mentais como alterações da atividade psíquica, envolvendo conceitos e categorias psicológicas (atividade, motivação-necessidade, personalidade). Por sua vez, a Psicopatologia baseia-se na psiquiatria clínica, operando com conceitos clínicos-médicos (etiologia, patogênese, sintoma e síndrome) e critérios patológicos gerais (surgimento e término da enfermidade). A primeira pauta-se no método psicológico-experimental, enquanto que a segunda no método clínico-descritivo, de cunho quantitativo.

Levantar essas diferenças é necessário para o esclarecimento desses dois âmbitos de intervenção em saúde mental. No entanto, não devem ser vistos como excludentes um ao outro, mas sim com o intuito de se buscar as convergências entre os dois campos, principalmente quando se trabalha com o paradigma atual em saúde mental, o da Atenção Psicossocial, marcado pelo trabalho interdisciplinar, multiprofissional, na atenção integral ao sujeito. Essa defesa é sustentada a partir da afirmação de Zeigarnik de que a psiquiatria sozinha não fornece um método capaz de trabalhar com o adoecimento mental do sujeito, uma vez que "a tentativa de estudar os distúrbios mentais isolados dos fatos da psicologia geral é equivalente à rejeição do conceito dialético materialista da mente como reflexo em outras partes do mundo" (Zeigarnik, 1962/1965, p. 3). Por isso sua defesa de reforçar os laços entre psicologia e psiquiatria com a criação de um ramo fronteiriço com outros campos científicos, o que é de grande relevância para a atuação em saúde mental na atualidade.

Zeigarnik (1976/1981) ressalta que a Patopsicologia não pode ser associada a uma pequena psiquiatria, mas deve se fortificar enquanto ciência psicológica. Como dito na entrevista a Golder (1986), para a autora é um ramo da psicologia vigotskiana, com os métodos psicológicos experimentais e uso de conceitos, categorias, termos específicos da ciência psicológica. Nesse sentido, a análise dos experimentos patopsicológicos deve ser efetuada com métodos correspondentes à teoria psicológica materialista, sendo que os resultados serão úteis para a prática clínica, complementando-a, mas também trazendo novos fatos.

Os princípios da Patopsicologia Experimental pautam-se também na Teoria da Atividade de Leontiev, esteio fundamental para o desenvolvimento e explicação dos transtornos mentais na relação entre atividade, personalidade e patologia. Portanto, segundo Zeigarnik (1976/1981), os processos psíquicos devem ser considerados como distintas formas de atividade psíquica, formadas no desenvolvimento ontogenético. A atividade do sujeito é mediatizada e regulada pelo reflexo psíquico da realidade, que conduz as necessidades, os motivos, as finalidades e as condições de sua atividade, como também regula as ações e modos de operações (Leontiev, 1978).

Sobre os pressupostos metodológicos, este campo psicológico sustenta-se sob o desenvolvimento de métodos experimentais, além das análises teóricas acerca de diferentes alterações mentais e a compreensão dos processos mentais normais. Zeigarnik (1962/1965, 1969/1979, 1976/1981) faz críticas e apontamentos sobre os limites do princípio da medição quantitativa, a utilização de testes padronizados e a tentativa de determinação da personalidade por meio de testes projetivos, destacando que tais procedimentos pouco explicam sobre o processo de adoecimento.

Em contraponto com os testes e o método projetivo, a autora propõe a investigação psicológica experimental no trabalho junto aos processos patológicos do psiquismo. A partir da Psicologia Histórico-Cultural, as funções psíquicas são entendidas não como funções inatas, mas sim como produto das atividades desenvolvidas ao longo da vida, o que faz com que as alterações psíquicas sejam compreendidas e investigadas como resultantes das alterações da atividade. Desse modo, é possível a análise qualitativa das distintas formas de desintegração do psiquismo, a descoberta dos mecanismos da atividade alterada e as possiblidades para sua reabilitação.

Tem-se que os experimentos patopsicológicos devem ser "capazes de atualizar as operações mentais 
que o sujeito utiliza em sua atividade vital e os motivos que provocam esta atividade" (Zeigarnik, 1976/1981, p. 28), na passagem, para a situação experimental, de seu modo de atividade no cotidiano. A psicóloga lituana sustenta com firmeza que é sempre necessário contrapor o diagnóstico patopsicológico com a história clínica, ou seja, "analisar os contrastes e semelhanças entre os dados obtidos pelas investigações patopsicológicas, por um lado, e os obtidos da história do paciente, por outro. O fundamental consiste em não se deixar com uma só destas determinações, sem sair delas" (Zeigarnik, citada por Golder, 1986, p. 90).

A partir do exposto, compreende-se que o experimento coloca o sujeito em atividade, de um modo que se aproxime ao máximo das situações por ele vividas e nas quais ele tenha que encontrar recursos psíquicos para resolvê-la. Os dados obtidos nos experimentos, os quais envolvem a participação ativa do experimentador (não somente como observador), são considerados na interrelação da história singular do paciente (ontogênese), mas também nos nexos com os aspectos macroestruturantes da personalidade, tais como os aspectos políticos, econômicos e sociais da realidade do sujeito e a classe social a qual pertence. Ainda, ao ater-se à história pregressa do sujeito, tal levantamento não tem a característica de uma anamnese comum na qual muitas vezes se dá destaque à cronologia das aquisições (locomoção, fala, controle de esfíncteres, escolarização), mas se busca a dinâmica das relações sociais que constituíram o psiquismo do sujeito adoecido, verificando-se o desenvolvimento cultural anteriormente alcançado e o que há de preservado no mesmo.

O método experimental patopsicológico, portanto, segue três direções principais (Golder,1986; Zeigarnik, 1962/1965): o experimento psicológico objetivando o diagnóstico diferencial; o experimento psicológico para a análise da estrutura da alteração do processo, e; o experimento psicológico para investigar o grau de alteração da atividade mental (importância na área jurídica e industrial, por exemplo).

Assim, a Patopsicologia Experimental, de acordo com a bibliografia consultada, trabalharia com os seguintes experimentos psicológicos: classificação de objetos; exclusão do objeto inadequado (quarto excluído); método pictográfico; evocação mediatizada; compreensão do sentido figurado; estabelecimento da consecutividade de fatos e variantes do método associativo.
A partir disso, tem-se a defesa de uma avaliação qualitativa detalhada, juntamente com os processos de intervenção, baseada nos princípios da Psicologia Histórico-Cultural. A Patopsicologia Experimental propõe uma nova abordagem para a avaliação psicológica, que considera o caráter ativo e integral da atividade mental, através de técnicas experimentais, com a importância da psicologia da personalidade, da motivação e da atividade humana. Ademais, tem o homem, o ser social por excelência, como princípio explicativo principal, na superação de tendências biologizantes, quando se depara com os fenômenos que levam às alterações da personalidade e da relação que o homem estabelece com o meio social (Zeigarnik, 1962/1965, 1969/1979, 1976/1981).

A esse respeito, quando desenvolve a Patopsicologia Experimental, Zeigarnik analisa os problemas do sujeito adoecido não somente como produto de suas lesões ou traumatismos cerebrais, mas sim no quadro dinâmico de sua personalidade total, influenciada por sua história individual e pelos conflitos originados na estrutura complexa das relações interpessoais (Braslavsky, 1986). A própria autora afirma que "a doença mental lesiona com frequência a personalidade em seu conjunto, troca o sistema de suas necessidades, de suas particularidades volitivo-emocionais" (Zeigarnik, 1969/1979, p. 108).

Faz-se necessário, mesmo que de modo pontual, assinalar a relevância da personalidade no processo de adoecimento psíquico, visto que foi prioridade nas investigações finais de Zeigarnik. Nesse sentido, a personalidade constitui-se pela unificação e vinculação das atividades do sujeito em sua vida, dentro do sistema de relações objetivas da sociedade. Em outras palavras, é no processo de apropriação do mundo dos objetos e fenômenos criados pela humanidade, no processo de socialização, por meio da atividade humana, que irão aparecer necessidades, motivos e interesses, que constituem a formação da personalidade do homem. No seio das condições histórico-sociais, "a personalidade não nasce, a personalidade se faz" (Leontiev, 1978, p. 137).

Logo, o papel exercido pela atividade alterada do homem atuará em seu modo de vida e, desse modo, em sua personalidade, o que justifica o fato de que os processos patológicos modificados devem ser analisados a partir das formas de atividade. Entende-se, portanto, que o transtorno mental atua na personalidade de maneira indireta, alterando a atividade assimilada ao longo do 
desenvolvimento social. A esse respeito, é interessante a afirmação de Alvarez e Grau Abalo (1992), autores cubanos que trabalharam com os pressupostos patopsicológicos no estudo do desenvolvimento anômalo da personalidade, que expõem que "para as questões etiológicas e problemas patogênicos, o problema do desenvolvimento da personalidade, sob a influência de condições sociais, torna-se uma problemática teórica de primeira ordem" (p. 122).

Portanto, assim como no desenvolvimento normal, na ontogenia, a alteração psicológica da personalidade, sua autoconsciência, realiza-se na atividade prática do sujeito, "na reestruturação de suas relações reais, neste caso sob a influência de uma interpretação delirante de seu estado, desenvolvida com a autopercepção e que se refere ao lugar que ocupa a pessoa entre as demais pessoas" (Zeigarnik, 1976/1981, p. 51).

Em síntese, para a Patopsicologia Experimental, o processo de adoecimento psíquico faz com que os processos já formados dos motivos e necessidades sejam destruídos como também incide na formação de novos motivos (patologicamente alterados) e de novas propriedades e características da personalidade. Também, o processo de adoecimento mental, decorrente da alteração da estrutura da atividade humana, faz com que os motivos percam sua função de criar significados e dar sentido pessoal à atividade humana, como alteram a função de autocontrole do comportamento.

Além do passo a frente em relação às tendências predominantemente biológicas e a-históricas, é válido, por fim, assinalar o valor das investigações patopsicológicas assinalados por Zeigarnik em todos os seus livros consultados. Desse modo, tem-se que o material patopsicológico permite observar a estrutura das distintas formas da atividade psíquica, em outras palavras, possibilita a análise da estrutura dos motivos, necessidades e interesses humanos, por meio do uso dos experimentos psicológico e as intervenções sob o escopo teórico da Patopsicologia Experimental.

\section{Considerações finais}

Ao final desse percurso, constata-se que a Psicologia Histórico-Cultural oferece fundamento teórico para a compreensão do sofrimento e adoecimento psíquico. Portanto, além de discussões concernentes ao âmbito escolar, dos processos de ensino e aprendizagem, a psicologia vigotskiana fornece uma concepção dos transtornos mentais, atrelada às determinações históricas e sociais, para o trabalho no campo da saúde mental. Esse é o campo compreendido pela Patopsicologia Experimental, constituída pela autora de referência deste artigo, Bluma V. Zeigarnik.

Ao se pautar na estrutura da atividade humana, com suas alterações patológicas, Zeigarnik defende que a patologia age na personalidade, na intrínseca relação entre as condições sociais, o desenvolvimento psíquico e o desencadeamento do adoecimento psíquico. Todo o caminho percorrido no artigo é de uma investigação bastante profícua, uma vez que Zeigarnik é autora pouco conhecida e pesquisada no Brasil, sendo a Patopsicologia Experimental um campo do conhecimento pouco explorado. Nesta perspectiva, encontra-se um novo lugar social para as pessoas em sofrimento mental, pensando no sujeito que sofre a partir de sua vivência de sofrimento, em condições concretas de vida.

Toda a discussão apresentada no decorrer do artigo é importante por oferecer fundamentos para pensarmos a situação atual brasileira, de medicalização e patologização da vida, assim como da atuação do psicólogo diante das demandas com as quais se depara no campo da saúde mental. Portanto, abrem-se caminhos para novas hipóteses de trabalho, para possibilidades diferentes de atuação em saúde mental numa época de convulsão social, considerando os fatores sociais como patogênicos e suas implicações na desintegração da atividade vital humana, incidindo na formação e (de) formação da personalidade, como foi assinalado logo no início do presente artigo.

Diante disso, a atuação com base na Patopsicologia Experimental pode instrumentalizar o profissional para a avaliação e intervenção das alterações patológicas dos processos psicológicos, indo além das vivências imediatas do sujeito, por esboçar o processo da atividade psíquica alterada, suas motivações e outros fatores que estão implicadas no curso do sofrimento mental. Há, nesse sentido, uma convergência com o paradigma atual em saúde mental caracterizado pela concepção da Atenção Psicossocial, que pensa o plano de cuidados dos sujeitos atentando-se às condições de vida e às múltiplas determinações do processo de saúde e doença, no cuidado compartilhado entre a equipe multiprofissional e a Rede de Atenção à Saúde Mental. Há, ainda, a possibilidade de articulação, pelo caráter de complementariedade apresentado pela Patopsicologia Experimental, entre o campo científico da psicologia e o da psiquiatria, o que é requerido na RAPS (Rede de Atenção Psicossocial) no cuidado de sujeitos em sofrimento mental no âmbito do Sistema Único de Saúde (SUS) no Brasil. 
A partir deste artigo, é válido ressaltar a contradição que a sociedade atual apresenta, pautada no fato de ser uma produtora em série de adoecimento psíquico, mas que lida apenas com o "verniz" do mesmo, isto é, mantém-se apenas na aparência dos fenômenos e não voltada a sua "engrenagem", à essência. Nesta postura fenomenológica e paliativa, incidem os investimentos na indústria farmacológica e, consequentemente, vemos os altos índices de venda de medicação, principalmente, os psicotrópicos, ignorando as condições que produzem o adoecimento. Dessa maneira, defende-se o fato evidente de que o tratamento medicamentoso não pode e nem deve ser a única condição para que o sujeito recupere o controle de suas funções psíquicas. Há que se pensar em condições terapêuticas que não se voltem somente ao sujeito especificamente, mas às relações concretas que produziram a sua patologia.

Por fim, essa discussão possibilita o estabelecimento da relação entre o desencadeamento das patologias mentais e a organização do trabalho sob os lençóis capitalistas, na constatação paradoxal entre a atividade trabalho como fator de humanização, em termos ontológicos, e o trabalho que assume determinadas características desumanizadoras e desagregadoras em determinadas sociedades e classes sociais. Na interdependência entre as condições objetivas de vida e a formação do psiquismo humano, é possível pensar a relação entre os processos sociais e o desencadeamento do adoecimento psíquico.

Desse modo, o desenvolvimento psíquico humano não pode ser descolado das relações de classe e de produção capitalistas, no caso do atual contexto histórico. Se as relações sociais, mediadas por instrumentos e signos, levam à formação psicológica, em suas formas saudáveis como também patológicas, o presente artigo permite o entendimento de que quanto mais patogênicas tais relações forem, mais patogênico pode transformar-se o psiquismo humano. A esse respeito, é possível assinalar as contradições que se colocam no interior da sociedade capitalista, que não podem ser esgotados nessas páginas, mas são válidos os questionamentos: Como promover saúde psíquica em condições que produzem adoecimento? Que limites e que possibilidades podem se apresentar no seio da sociedade capitalista e suas contradições?

Com apontamentos iniciais no presente artigo, espera-se estabelecer uma base sólida a partir deste referencial teórico para uma atuação pautada no seu comprometimento ético e político, atenta para essas condições sociais patogênicas, buscando-se formas para transformá-la no âmbito individual e coletivo de atuação na esfera da saúde mental. Ao fundamentar a atuação do psicólogo, este posicionamento teórico e prático pode, portanto, superar a tendência recorrente de culpabilização do indivíduo pelo sofrimento psíquico, ao reconhecer nas formas materiais de vida as condições objetivas para o desenvolvimento humano, saudável ou não.

Frente ao exposto, é possível afirmar o quanto são relevantes as investigações na área da saúde mental e, mais especificamente, às pessoas com transtornos mentais mais severos, buscando-se a sistematização de procedimentos clínico-terapêuticos pautados na Psicologia Histórico-Cultural. Esta empreita deve ser realizada coletivamente e este estudo pretende acenar com novas possibilidades de investigação e aprofundamento das pesquisas de autores soviéticos como Zeigarnik, ainda pouco conhecidos no Brasil.

\section{Referências}

Almeida, S. H.V. (2008). Psicologia histórico-cultural da memória (Tese de Doutorado). Pontifícia Universidade Católica de São Paulo, São Paulo. Recuperado de http://livros01.livrosgratis.com.br/cp056390. pdf

Alvarez, A. A., \& Abalo, J. G. (1992). Algunas consideraciones sobre el papel del desarrollo anómalo de la personalidad en la aparición de la neurosis. Revista Cubana de Psicologia, 9(2), 120-125.

Antunes, R. (2011). Adeus ao trabalho? Ensaio sobre as metamorfoses e a centralidade do mundo do trabalho (15 ${ }^{\mathrm{a}}$ ed.). São Paulo: Cortez.

Boarini, M. L. (2006). A loucura no leito de Procusto. Maringá: Dental Press.

Braslavsky, B. P. (1986). Prefácio. In M. Golder (Org.), Reportajes contemporaneos a la Psicologia Sovietica (pp. 9-13). Buenos Aires: Editorial Cartago.

Lefebvre, H. (1983). Lógica formal/lógica dialética (3ª ed). Rio de Janeiro: Civilização Brasileira.

Golder, M. (1986). Entrevista com B. V. Zeigarnik. In M. Golder (Org.), Reportajes contemporaneos a la Psicologia Sovietica (pp. 72-112). Buenos Aires: Editorial Cartago.

Lavretsky, H. (1998). The Russian concept of schizophrenia: a review of the literature. Schizophrenia Bulletin, 24(4), 537-557. Recuperado de http://schizophreniabulletin.oxfordjournals.org/content/24/4/537. full.pdf

Leontiev, A. N. (1978). Actividad, consciencia y personalidad. Buenos Aires: Ediciones Ciencias del hombre.

Organização Mundial de Saúde (OMS) (2001). Relatório sobre a saúde no mundo. Saúde mental: Nova concepção, nova esperança. Washington, D.C.: Genebra.

Rojlin, L. (s.d.). La medicina soviética en la lucha contra las enfermedades psíquicas. Moscú: Ediciones en lenguas extranjeras.

Shuare, M. (1990). La psicología soviética tal como yo la veo. Moscú: Editorial Progresso. 
Patopsicologia Experimental: Abordagem histórico-cultural para o entendimento do sofrimento mental

Valsiner, J., \& Van der Veer, R. V. (2006). Vygotsky: uma síntese. (5ª ed.). São Paulo: Edições Loyola.

Vygotsky, L. (1930). A transformação socialista do homem. Marxists Internet Archive (Nilson Dória, Trad.). Recuperado de http://www. marxists.org/portugues/vygotsky/1930/mes/transformacao.htm

Wortis, J. (1953). La psiquiatría soviética. Buenos Aires: El Ateneo.
Zeigarnik, B. V. (1965). The pathology of thinking. Nova lorque: Consultants Bureau (Obra original publicada em 1962)

Zeigarnik, B. V. (1979). Introducción a la Patopsicologia. La Habana: Científico Técnica (Obra original publicada em 1969)

Zeigarnik, B. V.(1981). Psicopatologia. Madrid: Akal Editor (Obra original publicada em 1976)

\footnotetext{
${ }^{1}$ Mais especificamente, pode-se fazer menção ao DSM (Manual de Diagnóstico e Estatística das Perturbações Mentais) e ao CID (Classificação Internacional das Doenças e Problemas relacionados à Saúde), ambos em edições sempre revistas e ampliadas.

${ }^{2}$ Foge ao escopo do texto realizar uma discussão aprofundada sobre a vinculação dos autores elaboradores da Psicologia Histórico-Cultural ao marxismo, considerando as diversas correntes interpretativas existentes. Há o chamado marxismo ocidental que não é homogêneo, como também não foi o chamado marxismo desenvolvido no interior da URSS. Para melhor elucidar esta questão, remetemos o leitor à leitura de Tuleski, S. C. (Org.). (2015). Vygotsky and Leontiev: The construction of a Marxist Psychology. New York: NOVA Publishers.

${ }^{3} \mathrm{O}$ presente artigo pretende trabalhar apenas com as contribuições da Patopsicologia Experimental dadas por sua autora principal, Bluma V. Zeigarnik, pelo espaço e objetivo proposto. Sabe-se da contribuição importante de autores como Yves Clot, médico francês que desenvolveu a "Clínica da Atividade" no campo da psicologia do trabalho, baseando-se em Vigotski, Leontiev e Bahktin: Clot, Y. (2006). A função psicológica do trabalho. Petrópolis, RJ: Vozes. Outro autor francês de relevância é Lucien Sève, com seus estudos sobre a pesonalidade a partir do referencial marxista: Sève, L. (n.d.). Marxismo e teoria da personalidade. Vol I, II e III. Lisboa, Livros Horizonte.

${ }^{4}$ A categoria superação é uma das categorias da dialética. Lefebvre (1983) afirma que, na superação, o superado, por um lado, é suprimido, o que indica o que afirmamos acerca do aspecto biológico no desenvolvimento humano, que passa a um plano secundário. No entanto, o autor destaca que, por outro lado, "o superado não deixa de existir, não recai no puro e simples nada; ao contrário, o superado é elevado a nível superior. E isso porque ele serviu de etapa, de mediação para a obtenção do 'resultado' superior; certamente, a etapa atravessada não mais existe em si mesma, isoladamente, como ocorria num estágio anterior; mas persiste no resultado através da sua negação" (Lefebvre, 1980, pp. 230-231).
}

Maria Aparecida Santiago da Silva, Mestre em Psicologia pela Universidade Estadual de Maringá (UEM), é psicóloga do Centro de Atenção Psicossocial (CAPS) I de Marialva/PR. Endereço para correspondência: Rua Elvira Lavorenti Perego, 157. Bairro Parque Avenida - Maringá/Paraná. CEP: 87025-560. Telefones para contato: (44) 3034-8142 e (44) 9856-5401.E-mail: maria_sansilva@hotmail.com

Silvana Calvo Tuleski, Doutora em Educação Escolar pela Universidade Estadual Paulista (UNESP) de Araraquara, é Professora Associada do Departamento de Psicologia da Universidade Estadual de Maringá (UEM) e docente do Programa de Pós-graduação em Psicologia na Universidade

Estadual de Maringá (UEM). E-mail: silvanatuleski@gmail.com 